\title{
Using Interval Operations in the Hungarian Method to Solve the Fuzzy Assignment Problem and Its Application in the Rehabilitation Problem of Valuable Buildings in Egypt
}

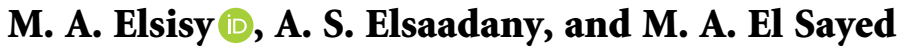 \\ Benha Faculty of Engineering, Benha University, Benha, El Qalyoubia, Egypt \\ Correspondence should be addressed to M. A. Elsisy; mohamedelsisy2@gmail.com
}

Received 21 May 2020; Revised 23 August 2020; Accepted 29 August 2020; Published 14 September 2020

Academic Editor: Baltazar Aguirre Hernandez

Copyright (c) 2020 M. A. Elsisy et al. This is an open access article distributed under the Creative Commons Attribution License, which permits unrestricted use, distribution, and reproduction in any medium, provided the original work is properly cited.

\begin{abstract}
Assignment problem (AP) is an entrenched tool for solving engineering and management problems. The Hungarian method is always used to fathom the AP in crisp cases. This paper presents an algorithm of finding the optimum solution of the fuzzy AP by using the modified Hungarian method. This method is utilized to get a minimum assignment cost in the fuzzy environment for a fuzzy AP. Firstly, we use the fuzzy numbers without any transformation. Secondly, the fuzzy AP is transformed into an interval AP based on the $\alpha$-cut methodology. Then, the interval arithmetic operations and the order relations are applied to get the optimal solution by utilizing the modified Hungarian method. The proposed algorithm requires less efforts and time to reach optimality, compared to the existing methods. Numerical examples are given to ensure the efficiency and the validity of the proposed algorithm. A study on the reuse of many valuable buildings is presented after using different government and service buildings in a manner that does not fit with its original function and heritage value. We offer a solution based on the scientific and realistic basis for requalification according to the variables and requirements of the social, cultural, and economic environments in the environment surrounding the valuable buildings.
\end{abstract}

\section{Introduction}

The assignment problem (AP) is a very much evolved advancement issue in engineering and management sciences and has been broadly applied in both assembling and administration frameworks $[1,2]$. In an AP, $n$ jobs are to be performed by $n$ people contingent upon their proficiency to carry out the job. The AP is used to determine the issue of appointing several origins to the equal number of destinations at the very least expense or most extreme benefit in the most ideal manner. It can appoint people to employments, classes to rooms, administrators to machines, drivers to trucks, trucks to conveyance courses, or issues to investigate groups, and so forth.

To deal with the AP, the decision parameters of the model must be fixed at deterministic values. In any case, to show real issues and to perform estimations, we ought to manage vulnerability and vagary. These vulnerability and vagary are a result of estimation botch, unraveling of physical models, assortments of the boundaries of the system, computational bungles, etc. Along these lines, we cannot viably use traditional old-style task issues, and from this time forward, the usage of fuzzy undertaking issues is progressively legitimate [3-8].

Several algorithms have been exhibited to solve APs, such as linear programming $[1,9,10]$, Hungarian algorithm [11, 12], and particle swarm optimization [9]. Kar et al. resolved an AP with fuzzy cost by Yager's ranking index which transforms the fuzzy AP into a crisp one [7]. Different membership functions and the Yager ranking index for solving fuzzy APs and fuzzy travelling salesman problems were introduced by Kumar and Gupta [13]. Tapkan et al. considered a multiobjective generalized AP directly via bee's algorithm and fuzzy ranking [10]. Emrouznejad set up an algorithm using the data envelopment analysis method to solve the APs with fuzzy costs or fuzzy profits [3]. A new 
method for solving fuzzy assignment problems was given by Pandian and Kavitha [14]. Thorani and Shankar explained in detail the application in the fuzzy AP [15]. Mary and Selvi proposed a model to solve the fuzzy AP using the centroid ranking method [16]. In [17], Traneva and Tranev presented the interval-valued intuitionistic fuzzy AP, in which the costs of assigning jobs to candidates are interval-valued intuitionistic fuzzy, depending on the experience, the education, and the professionalism of the applicants.

A basis in modeling uncertain systems is that an entangled model is not generally important to manage incomplete information and inaccurate data [18]. Interval numbers are a structure which helps to stay away from such an unnecessary complexity. Moore originally introduced interval numbers [19]. An interval number is a number whose exact value is unknown, but a range within which the value lies is known [20]. An interval number permits an expert to make his/her approximations about boundaries on a span as opposed to a crisp number. This adaptability caused interval numbers to have extraordinary applications in optimization issues. The literature studies on the applications of interval number in decision-making problems are so wide [21-23].

In most of the real-world problems, the parameters such as cost, time, and profit may not be precisely known in advance due to several uncontrollable factors such as human judgements and market fluctuations. In such situations, considering the values of uncertain parameters as fuzzy numbers or interval numbers is better than to approximate them as crisp values [21-25]. This led us to introduce the fuzzy AP that we transform into an interval AP.

The urban design and the architectural character represent an expressive characteristic of the prevailing culture in the society for the civilized value; the civilized value in architecture and urbanism reaches its highest levels when it is related to cultural connotations and concepts, so the negligence or neglect of civilizational heritage that enriches architecture and urbanism is only a lack of national awareness of civilized values wasting national wealth and retreating to the cultural dimension of the society [26-31]. As a result of accelerated urban development which is not indifferent to civilizational and heritage values during the second half of the twentieth century in Egypt, many distinguished buildings began to disappear to be replaced by other buildings that do not rise to the same architectural value, for example, the use of many valuable buildings as various government and service buildings in a manner that is not commensurate with their original function and heritage value, which led to deformation and visual pollution that has become a phenomenon in many Egyptian cities. We use some valuable buildings in the Arab Republic of Egypt as a comparative study. Their value is defined as being one of the philosophical concepts that can be described as "the criterion governing the degree to which a person accepts what is around him according to his desires and needs." This is because the value is a relative influence that depends on the nature of the recipient and the constituent conditions of his personality and on the temporal and spatial conditions. Also, most forms of the value are not acquired by the building during its design but rather over time [26-31]. The goal of reuse is to preserve historical buildings that are considered national wealth and part of the national economy, creating positive change in the population through contact with visitors, learning about new habits and lifestyles, and cultural exchange; however, the presence of some tourist establishments in areas of a somewhat conservative social nature does not contradict customs and traditions. It is preferable to reuse valuable buildings with an activity similar to the original activity for which the building was established as possible or by studying the needs of the surrounding environment and adapting the new activity according to the requirements of the surrounding environment.

In this article, the modified Hungarian method is introduced to solve the fuzzy AP. In our proposed model, due to several uncontrollable factors such as human judgements and market fluctuations, the cost is considered as a fuzzy number. The primary objective of this study is to propose a new method for solving the AP under an uncertain situation. Firstly, the fuzzy numbers are used without any transformation. Secondly, the fuzzy AP is transformed into an interval AP based on the $\alpha$-cut methodology. Then, the interval arithmetic operations are applied to obtain the optimal solution by utilizing the modified Hungarian method. Also, the reuse and employment of the valuable buildings in Egypt are studied. It is used to clarify the impact on neighboring urban entities, which may help to find an economic basis on which to maintain those buildings to enter within the organic entity of the old city.

The composition of the article is organized as follows: preliminaries and notions of the fuzzy and interval numbers are reviewed in Section 2. Section 3 presents the mathematical formulation of the fuzzy AP. Section 4 provides the procedures for the modified Hungarian method. Also, numerical examples are presented in Section 4. In Section 5, we study the reuse and employment of the valuable buildings in Egypt. Finally, the conclusion is given in Section 6.

\section{Preliminaries and Notions}

In this section, some essential ideas and preparatory outcomes utilized as a part of this paper are quickly presented.

Definition 1 (fuzzy numbers). Let $R^{1}$ be the set of all real numbers. Then, a real fuzzy number $\widetilde{a}$ is defined by its membership function $\mu_{\tilde{a}}(x)$ that satisfies $[4,32,33]$

(1) A continuous mapping from $R^{1}$ to the closed internal $[0,1]$

(2) $\mu_{\tilde{a}}(x)=0$ for all $x \in(-\infty, a]$

(3) Strictly increasing and continuous on $[a, b]$

(4) $\mu_{\tilde{a}}(x)=1$ for all $x \in[b, c]$

(5) Strictly decreasing and continuous on $[c, d]$

(6) $\mu_{\mathfrak{a}}(x)=0$ for all $x \in[d,+\infty)[8]$ 
Definition 2 (triangular fuzzy number). $\tilde{a}=\left(a_{0}, b, c\right)$ is a triangular fuzzy number, where $a_{0}$ is the smallest value, $b$ is the main value, and $c$ is the highest value. The membership function $\mu_{a}(a ; \vartheta), \vartheta \in[0,1]\left(0 \leq \mu_{a}(a ; \vartheta) \leq \delta\right)$, where $\vartheta$ is the maximum value and $a=b$. Then $[4,32,33]$,

$$
\mu_{a}(a ; \vartheta)= \begin{cases}0, & \text { if } a<a_{0}, \text { or } a>c, \\ \frac{\left(a-a_{0}\right) \vartheta}{b-a_{0}}, & \text { if } a_{0} \leq a \leq b, \\ \frac{(c-a) \vartheta}{c-b}, & \text { if } b \leq a \leq c .\end{cases}
$$

Definition 3 (the level set). The $\alpha$-level set of the fuzzy number $\widetilde{a}$ is defined as an ordinary set $L_{\alpha}(\widetilde{a})$ for which the degree of its membership function exceeds the level set $\alpha \in[0,1]$, where $[6,32,33]$

$$
L_{\alpha}(\widetilde{a})=\left\{a \in R^{m} \mid \mu_{a}(x) \geq \alpha\right\}=\left\{a \in\left[\widetilde{a}_{\alpha}^{L}, a_{\alpha}^{U}\right] \mid \mu_{\tilde{a}}(x) \geq \alpha,\right\},
$$

where $\tilde{a}_{\alpha}^{L}=(1-\alpha) a_{0}+\alpha b, \tilde{a}_{\alpha}^{U}=(1-\alpha) c+\alpha b$, and $\tilde{a}_{\alpha}^{L}$ and $\widetilde{a}_{\alpha}^{U}$ represent the lower and upper cuts, respectively, as shown in Figure 1.

Definition 4 (interval numbers). An interval number is a number whose exact value is unknown, but a range within which the value lies is known [20]. Interval number is a number with both lower and upper bounds, $A=\left[a_{L}, a_{R}\right]$, where $a_{L} \leq a_{R}$. The interval is also denoted by its center and width as

$$
A=a_{C}, a_{W}=\left\{a: a_{C}-a_{W} \leq a \leq a_{C}+a_{W}, \quad a \in R\right\},
$$

where $a_{C}=\left(a_{L}+a_{R}\right) / 2$ and $a_{W}=\left(a_{R}-a_{L}\right) / 2$ are, respectively, the center and half width of $A[20,21,23]$.

The main arithmetic operations can be defined on interval numbers. Let $A=\left[a_{L}, a_{R}\right]=\left\{a: a_{L} \leq a \leq a_{R}, a \in R\right\}$ and $B=\left[b_{L}, b_{R}\right]=\left\{b: b_{L} \leq b \leq b_{R}, b \in R\right\}$.

$$
\begin{aligned}
A+B= & {\left[a_{L}, a_{R}\right]+\left[b_{L}, b_{R}\right]=\left[a_{L}+b_{L}, a_{R}+b_{R}\right], } \\
A-B= & {\left[a_{L}, a_{R}\right]-\left[b_{L}, b_{R}\right]=\left[a_{L}-b_{R}, a_{R}-b_{L}\right], } \\
A \times B= & {\left[\min \left(a_{L} b_{L}, a_{L} b_{R}, a_{R} b_{L}, a_{R} b_{R}\right),\right.} \\
& \left.\max \left(\left(a_{L} b_{L}, a_{L} b_{R}, a_{R} b_{L}, a_{R} b_{R}\right)\right)\right], \\
A \div B= & {\left[a_{L}, a_{R}\right] \times\left[\frac{1}{b_{R}}, \frac{1}{b_{L}}\right], } \\
k A= & k\left[a_{L}, a_{R}\right]= \begin{cases}{\left[k a_{L}, k a_{R}\right]} & \text { if } k \geq 0, \\
{\left[k a_{R}, k a_{L}\right]} & \text { if } k<0 .\end{cases}
\end{aligned}
$$

Definition 5. The order relation $\leq_{L R}$ between $A=\left[a_{L}, a_{R}\right]$ and $B=\left[b_{L}, b_{R}\right]$ is defined as $[21,23]$

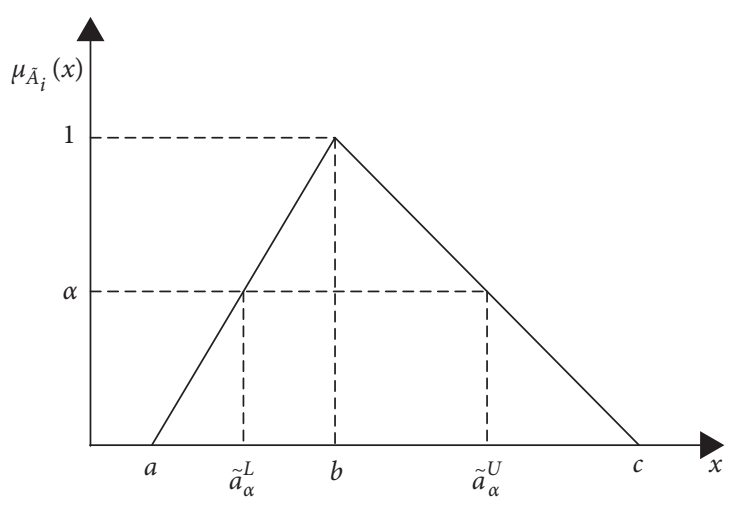

Figure 1: $\alpha$-Cut of the triangular fuzzy number.

$$
\begin{array}{ll}
A \leq_{L R} B & \text { iff } a_{L} \leq_{L} \text { and } a_{R} \leq b_{R} \\
A<_{L R} B & \text { iff } A \leq_{L R} B \text { and } A \neq B .
\end{array}
$$

This order relation $\leq_{L R}$ represents the decision maker's preference for the alternative with lower minimum cost and maximum cost, that is, if $A \leq_{L R} B$, then $A$ is preferred to $B$.

Definition 6. The order relation $\leq_{C W}$ between $A=a_{C}, a_{W}$ and $B=b_{C}, b_{W}$ is defined as $[20,21]$

$$
\begin{aligned}
& A \leq_{C W} B \quad \text { iff } a_{C} \leq b_{C} \text { and } a_{W} \leq b_{W}, \\
& A<_{C W} B \quad \text { iff } A \leq_{C W} B \text { and } A \neq B .
\end{aligned}
$$

This order relation $\leq_{C W}$ represents the decision maker's preference for the alternative with lower minimum cost and maximum cost, that is, if $A \leq_{C W} B$, then $\mathrm{A}$ is preferred to $\mathrm{B}$.

We use the sum of all elements of the interval/fuzzy number as a scale to compare between intervals/fuzzy numbers. Zero interval/zero fuzzy number is the sum of all elements of the interval/fuzzy number which is equal to zero.

\section{Fuzzy Assignment Problem}

In a general AP, " $n$ " works are to be performed by " $n$ " people depending on their efficiency to do the job in one-one basis such that the assignment cost is minimum or maximum $[24,34]$. If the objective of an AP is to minimize fuzzy cost $\widetilde{c}_{i j}$, then we provide the AP of $n \times n$ matrix each cell having a fuzzy number in Table 1.

Firstly, we transform the fuzzy cost $\widetilde{c}_{i j}$ into the interval cost $\left(\widetilde{c}_{i j}\right)_{\alpha}=\left[\left(\widetilde{c}_{i j}\right)_{\alpha}^{L},\left(\widetilde{c}_{i j}\right)_{\alpha}^{U}\right]$ by utilizing the $\alpha$-cut methodology. Thus, the fuzzy AP can be transformed into an interval AP with interval cost as shown in Table 2.

The above formulation of the problem is used in finding the optimal assignment when the values of parameters such as cost, time, and profit are precisely known in advance. However, in most of the realistic situations, the parameters such as cost, time, and profit may not be precisely known in advance due to several uncontrollable factors such as human judgements and market fluctuations. In such situations, considering the values of uncertain parameters as fuzzy numbers or interval numbers is better than to approximate 
TABLE 1: Fuzzy assignment problem.

\begin{tabular}{|c|c|c|c|c|c|c|c|c|}
\hline & & & & Worl & & & & \\
\hline & & & & 1 & $\ldots$ & $j$ & $\ldots$ & $n$ \\
\hline & 1 & $\tilde{c}_{11}$ & $\ldots$ & $\ldots$ & $\ldots$ & $\tilde{c}_{1 n}$ & & \\
\hline & $\ldots$ & $\ldots$ & $\ldots$ & $\ldots$ & $\ldots$ & $\ldots$ & & \\
\hline People & $i$ & $\ldots$ & $\ldots$ & $\tilde{c}_{i j}$ & $\ldots$ & $\ldots$ & & \\
\hline & $\ldots$ & $\ldots$ & $\ldots$ & $\ldots$ & $\ldots$ & $\ldots$ & & \\
\hline & $n$ & $\widetilde{c}_{n 1}$ & $\ldots$ & $\ldots$ & $\ldots$ & $\tilde{c}_{n n}$ & & \\
\hline
\end{tabular}

TABLE 2: Interval assignment problem.

\begin{tabular}{ccccccc}
\hline & & \multicolumn{5}{c}{ Works } \\
& & & 1 & $\ldots$ & $j$ \\
People & 1 & {$\left[\left(\widetilde{c}_{11}\right)_{\alpha}^{L},\left(\widetilde{c}_{11}\right)_{\alpha}^{U}\right]$} & $\ldots$ & $\ldots$ & $\ldots$ & {$\left[\left(\widetilde{c}_{1 n}\right)_{\alpha}^{L},\left(\widetilde{c}_{1 n}\right)_{\alpha}^{U}\right]$} \\
& $\ldots$ & $\ldots$ & $\ldots$ & $\ldots$ & $\ldots$ & $\ldots$ \\
& $\ldots$ & $\ldots$ & $\ldots$ & {$\left[\left(\widetilde{c}_{i j}\right)_{\alpha}^{L},\left(\widetilde{c}_{i j}\right)_{\alpha}^{U}\right]$} & $\ldots$ & $\ldots$ \\
& $\ldots$ & {$\left[\left(\widetilde{c}_{n 1}\right)_{\alpha}^{L},\left(\widetilde{c}_{n 1}\right)_{\alpha}^{U}\right]$} & $\ldots$ & $\ldots$ & $\ldots$ & $\ldots$ \\
\end{tabular}

them as crisp values. Mathematically, the fuzzy AP can be stated as $[5,7,35]$

$$
\begin{aligned}
& \min \quad \widetilde{Z}=\sum_{i=1}^{n} \sum_{j=1}^{n} \tilde{c}_{i j} x_{i j} \\
& \sum_{i=1}^{n} x_{i j}=1, \quad j=1,2, \ldots, n \\
& \sum_{j=1}^{n} x_{i j}=1, \quad i=1,2, \ldots, n, \\
& \begin{aligned}
x_{i j} & =0 \text { or } 1, \\
\text { for all } x_{i j} & = \begin{cases}1, & \text { if } i^{\text {th }} \text { person is assigned to } j^{\text {th }} \text { work, } \\
0, & \text { otherwise, }\end{cases}
\end{aligned}
\end{aligned}
$$

where $\widetilde{Z}$ denotes the fuzzy cost function, $\sum_{i=1}^{n} x_{i j}=1$ (one work is done by the $i^{\text {th }}$ person, $\left.i=1,2 \ldots, n\right)$, and $\sum_{j=1}^{n} x_{i j}=1$ (only one person must be assigned to $j^{\text {th }}$ work, $j=1,2 \ldots, n)$, where $x_{i j}$ denotes that $j^{\text {th }}$ work is to be assigned to the $i^{\text {th }}$ person. After applying the $\alpha$-cut methodology to the fuzzy AP, the following interval AP is obtained:

$$
\begin{aligned}
& \min \quad Z=\sum_{i=1}^{n} \sum_{j=1}^{n}\left[\left(\widetilde{c}_{i j}\right)_{\alpha}^{L},\left(\widetilde{c}_{i j}\right)_{\alpha}^{U}\right] x_{i j} \\
& \qquad \begin{array}{l}
\sum_{i=1}^{n} x_{i j}=1, \quad j=1,2, \ldots, n \\
\text { subject to } \quad \sum_{j=1}^{n} x_{i j}=1, \quad i=1,2, \ldots, n,
\end{array} \\
& \text { for all } x_{i j}= \begin{cases}1, & \text { if } i \text { th } \text { person is assigned to } j^{\text {th }} \text { work, } \\
0, & \text { otherwise, }\end{cases}
\end{aligned}
$$

where $\left(\widetilde{c}_{i j}\right)_{\alpha}^{L}$ and $\left(\widetilde{c}_{i j}\right)_{\alpha}^{U}$ are the lower and upper cuts of the fuzzy cost. In this study, we solve both fuzzy APs by converting them into the interval AP by using the modified Hungarian method. Making best use of the interval arithmetic operations and order relations, the modified Hungarian method solves the interval AP.

\section{The Proposed Algorithm}

The Hungarian method solves the minimization APs with $n$ workers and $n$ jobs. It has been presented in $[11,12,25]$. So, in this section, we explain how the modified Hungarian method deals with the fuzzy AP by using the fuzzy number without transforming or converting it into interval APs. We apply the $\alpha$-cut method to obtain the interval AP and use the interval arithmetic operations and the order relations to solve it. The modified Hungarian algorithm consists of the following four steps. The first two steps are executed once, while Steps 3 and 4 are repeated until an optimal assignment is found. The input of the algorithm is an $n \times n$ square matrix with only nonnegative elements. If the number of lines equals the number of rows (and columns), the test for the optimality is satisfied [17].

\section{Step 1. Subtract row minima:}

For each row, find the lowest interval and subtract it from each interval in that row based on interval arithmetic operations.

Step 2. Subtract column minima:

Similarly, for each column, find the lowest interval and subtract it from each interval in that column using interval arithmetic operations.

Step 3. Cover all zeros with a minimum number of lines:

Cover all zero or negative intervals in the resulting matrix using the minimum number of horizontal and vertical lines. If $n$ lines are required, an optimal assignment exists among the zeros or negative interval. The algorithm 
stops (an assignment can be made). If less than $n$ lines are required, continue with Step 4.

Step 4. Create additional zeros:

Determine the minimum uncovered interval (call it $\mathrm{H}$ ):

Subtract $\mathrm{H}$ from uncovered intervals.

(a) Add $\mathrm{H}$ to intervals covered by two lines

(b) Intervals covered by one line remain the same

(c) Then, go to Step 3

\section{Numerical Examples}

Example 1. Let us consider an AP with rows representing 4 people, $A, B, C$, and $D$, and columns representing 4 jobs, job I, job II, job III, and job IV. The cost matrix $\left[c_{i j}\right]$ is given whose elements are interval numbers. The problem is to find the optimal assignment so that the total cost of the job assignment becomes minimum, see Table 3 .

The minimum interval is $[1,5]$ in column $1,[3,7]$ in column $2,[1,5]$ in column 3 , and $[0,4]$ in column 4 . By using interval arithmetic operations, we get Table 4 .

The minimum interval is $[-4,4]$ in row $1,[-4,4]$ in row $2,[-4,4]$ in row 3 , and $[-2,6]$ in row 4 . By using interval arithmetic operations, we get Table 5.

The optimal assignment is $A \longrightarrow \mathrm{II}, B \longrightarrow \mathrm{IV}$, $C \longrightarrow \mathrm{III}$, and $D \longrightarrow \mathrm{I} . \quad$ Cost $=[3,7]+[3,7]+[1,5]+$ $[0,5]=[7,24]$.

Example 2 (see [25]). Let us consider a fuzzy AP with rows representing 4 people, $A, B, C$, and $D$, and columns representing 4 jobs, job I, job II, job III, and job IV. The fuzzy cost matrix $\left[\widetilde{c}_{i j}\right]$ is given whose elements are triangular fuzzy numbers. The problem is to find the optimal assignment so that the total cost of the job assignment becomes minimum, shown in Table 6. This example is solved by the method found in [25], in which the fuzzy assignment problem has been transformed into a crisp assignment problem using Robust's ranking indices [5].

Firstly, we apply the modified Hungarian method to the fuzzy cost matrix utilizing the arithmetic operations of fuzzy numbers to get the optimal assignment, see Table 7 .

The optimal assignment is $A \longrightarrow \mathrm{I}, B \longrightarrow \mathrm{III}$, $C \longrightarrow$ IV, and $D \longrightarrow$ II. The fuzzy optimal total cost $=(5$, $10,15)+(5,10,15)+(5,10,15)+(5,10,15)=(20,40,60)$.

Secondly, we apply the $\alpha$-cut methodology to obtain the interval cost matrix. Then, the modified Hungarian method is utilized with the help of the arithmetic operations of interval numbers to get the optimal assignment. We can transform the above problem elements into intervals at $\alpha=0.5$, shown in Table 8 .

We apply the proposed method on Table 8 to get Table 9 by using the arithmetic operations of the interval to get the optimal assignment.

The optimal assignment is $A \longrightarrow \mathrm{I}, B \longrightarrow \mathrm{III}$, $C \longrightarrow \mathrm{IV}$, and $D \longrightarrow$ II. We see the solution of the AP by our two methods is the same as the solution found in [25].
TABLE 3: Example 1.

\begin{tabular}{ccccc}
\hline & I & II & III & IV \\
\hline$A$ & {$[8,12]$} & {$[3,7]$} & {$[11,15]$} & {$[13,17]$} \\
$B$ & {$[1,5]$} & {$[7,11]$} & {$[16,20]$} & {$[0,5]$} \\
$C$ & {$[8,12]$} & {$[5,9]$} & {$[1,5]$} & {$[0,4]$} \\
$D$ & {$[3,7]$} & {$[9,13]$} & {$[7,11]$} & {$[5,9]$} \\
\hline
\end{tabular}

TABLE 4: Subtraction of the minimum interval in each column.

\begin{tabular}{ccccc}
\hline & I & II & III & IV \\
\hline$A$ & {$[3,11]$} & {$[-4,4]$} & {$[6,14]$} & {$[9,17]$} \\
$B$ & {$[-4,4]$} & {$[0,8]$} & {$[11,19]$} & {$[-4,4]$} \\
$C$ & {$[3,11]$} & {$[-2,6]$} & {$[-4,4]$} & {$[-4,4]$} \\
$D$ & {$[-2,6]$} & {$[2,10]$} & {$[2,10]$} & {$[1,5]$} \\
\hline
\end{tabular}

TABLE 5: Subtraction of the minimum interval in each row.

\begin{tabular}{ccccc}
\hline & I & II & III & IV \\
\hline$A$ & {$[-1,15]$} & {$[-8,8]$} & {$[2,18]$} & {$[5,21]$} \\
$B$ & {$[-8,8]$} & {$[-4,12]$} & {$[7,23]$} & {$[-8,8]$} \\
$C$ & {$[-1,15]$} & {$[-6,10]$} & {$[-8,8]$} & {$[-8,8]$} \\
$D$ & {$[-8,8]$} & {$[-4,12]$} & {$[-4,12]$} & {$[-5,7]$} \\
\hline
\end{tabular}

TABLE 6: Example 2.

\begin{tabular}{ccccc}
\hline & I & II & III & IV \\
\hline$A$ & $(5,10,15)$ & $(5,10,20)$ & $(5,15,20)$ & $(5,10,15)$ \\
$B$ & $(5,10,20)$ & $(5,15,20)$ & $(5,10,15)$ & $(10,15,20)$ \\
$C$ & $(5,10,20)$ & $(10,15,20)$ & $(10,15,20)$ & $(5,10,15)$ \\
$D$ & $(10,15,25)$ & $(5,10,15)$ & $(10,20,30)$ & $(10,15,25)$ \\
\hline
\end{tabular}

TABLE 7: Subtraction of the minimum interval in each column.

\begin{tabular}{ccccc}
\hline & I & II & III & IV \\
\hline$A$ & $(-10,0,10)$ & $(-10,0,15)$ & $(-10,5,5)$ & $(-10,0,10)$ \\
$B$ & $(-10,0,15)$ & $(-10,5,15)$ & $(-10,0,10)$ & $(-5,5,15)$ \\
$C$ & $(-10,0,15)$ & $(-5,5,15)$ & $(-5,5,15)$ & $(-10,0,10)$ \\
$D$ & $(-5,5,20)$ & $(-10,0,10)$ & $(-5,10,25)$ & $(-5,5,20)$ \\
\hline
\end{tabular}

TABLE 8: Transformation of Table 6 at $\alpha=0.5$.

\begin{tabular}{ccccc}
\hline & I & II & III & IV \\
\hline$A$ & {$[7.5,12.5]$} & {$[7.5,15]$} & {$[10,17.5]$} & {$[7.5,12.5]$} \\
$B$ & {$[7.5,15]$} & {$[10,17.5]$} & {$[7.5,12.5]$} & {$[12.5,17.5]$} \\
$C$ & {$[7.5,15]$} & {$[12.5,17.5]$} & {$[12.5,17.5]$} & {$[7.5,12.5]$} \\
$D$ & {$[12.5,20]$} & {$[7.5,12.5]$} & {$[15,20]$} & {$[12.5,20]$} \\
\hline
\end{tabular}

TABLE 9: Subtraction of the minimum interval in each column.

\begin{tabular}{ccccc}
\hline & I & II & III & IV \\
\hline$A$ & {$[-5,5]$} & {$[-5,7.5]$} & {$[-2.5,10]$} & {$[-5,5]$} \\
$B$ & {$[-5,7.5]$} & {$[-2.5,10]$} & {$[-5,5]$} & {$[0,10]$} \\
$C$ & {$[-5,7.5]$} & {$[0,10]$} & {$[0,10]$} & {$[-5,5]$} \\
$D$ & {$[0,12.5]$} & {$[-5,5]$} & {$[2.5,17.5]$} & {$[0,12.5]$} \\
\hline
\end{tabular}

Example 3 (see [4]). Let us consider a fuzzy AP with rows representing 4 people, $A, B, C$, and $D$, and columns representing 4 jobs, job I, job II, job III, and job IV. The fuzzy cost matrix $\left[\widetilde{c}_{i j}\right]$ is given whose elements are trapezoidal fuzzy numbers. The problem is to find the optimal assignment so that the total fuzzy cost of the job assignment becomes minimum, shown in Table 10. This example is 
TABLE 10: Example 3.

\begin{tabular}{ccccc}
\hline & I & II & III & IV \\
\hline$A$ & $(3,5,6,7)$ & $(5,8,11,12)$ & $(9,10,11,15)$ & $(5,8,10,11)$ \\
$B$ & $(7,8,10,11)$ & $(3,5,6,7)$ & $(6,8,10,12)$ & $(5,8,9,10)$ \\
$C$ & $(2,4,5,6)$ & $(5,7,10,11)$ & $(8,11,13,15)$ & $(4,6,7,10)$ \\
$D$ & $(6,8,10,12)$ & $(2,5,6,7)$ & $(5,7,10,11)$ & $(2,4,5,7)$ \\
\hline
\end{tabular}

solved by the method found in [4]. In [4], the fuzzy AP was transformed into a crisp AP in the LPP form.

Firstly, we apply the modified Hungarian method to the fuzzy cost matrix utilizing the arithmetic operations of fuzzy numbers to get the optimal assignment, see Tables 11-13.

The optimal assignment is $A \longrightarrow \mathrm{III}, B \longrightarrow \mathrm{II}$, $C \longrightarrow \mathrm{I}$, and $D \longrightarrow \mathrm{IV}$. The fuzzy optimal total cost is calculated as $(2,4,5,7)+(9,10,11,15)+(2,4,5,6)+$ $(2,4,5,7)=(16,23,27,35)$.

Secondly, we apply the $\alpha$-cut methodology to obtain the interval cost matrix. Then, the modified Hungarian method is utilized with the help of the arithmetic operations of interval numbers to get the optimal assignment. If the fuzzy number in the above problem transformed into interval at $\alpha=0.5$, shown in Table 14 .

We apply the proposed method on Table 14 to get Table 15 by using the arithmetic operations of the interval. Also, we get Tables 16 and 17 .

The optimal assignment is $A \longrightarrow \mathrm{III}, B \longrightarrow \mathrm{II}, C \longrightarrow \mathrm{I}$, and $D \longrightarrow \mathrm{IV}$. We see the solution of the AP by our two methods is the same as the solution found in [25].

In the above examples, the fuzzy optimal total cost obtained by our two methods remains the same as that obtained by other methods.

\section{Practical Application}

In this section, we get acquainted with some basic definitions for the application study. First, a building of value (with a distinct architectural style) is defined as a building or facility that is distinguished by the historical, symbolic, architectural, artistic, urban, or social value. Also, it has been agreed that buildings and heritage installations of distinct architectural style should be characterized by accepting and positively interacting with the community, being expressive of material, moral, or intellectual phenomena in a specific period (social or cultural phenomenon). Its condition allows to be present and able to deal with it, and this is known as persistence and continuity. Heritage buildings are classified according to their condition into several levels, some of which are good, partially degraded, and totally degraded. The aim of this classification is to set priorities for dealing with heritage buildings as most important buildings are placed on top of the priorities of conservation plans [26-31]. A strategy for re-employment of valuable buildings is the creation of a job for the building other than the one for which it was established, and this employment may be accompanied by making some fundamental changes to the building to fit with the newly created job and an optional reemployment of buildings in the case of valuable buildings
TABLE 11: Subtraction of the minimum interval in each column.

\begin{tabular}{ccccc}
\hline & I & II & III & IV \\
\hline$A$ & $(-4,-1,1,4)$ & $(-2,2,6,9)$ & $(2,4,6,12)$ & $(-2,2,5,8)$ \\
$B$ & $(0,2,5,8)$ & $(-4,-1,1,4)$ & $(-1,2,5,9)$ & $(-2,2,4,7)$ \\
$C$ & $(-4,-1,1,4)$ & $(-1,2,6,9)$ & $(2,6,9,13)$ & $(-2,1,3,8)$ \\
$D$ & $(-1,3,6,10)$ & $(-5,0,2,5)$ & $(-2,2,6,9)$ & $(-5,-1,1,5)$ \\
\hline
\end{tabular}

TABLE 12: Subtraction of the minimum interval in each row.

\begin{tabular}{ccccc}
\hline & $\mathrm{I}$ & II & III & IV \\
\hline$A$ & $(-8,-2,2,8)$ & $(-6,1,7,13)$ & $(-7,-2,4,14)$ & $(-7,1,6,13)$ \\
$B$ & $(-4,1,6,12)$ & $(-8,-2,2,8)$ & $(-10,-4,3,11)$ & $(-7,1,5,12)$ \\
$C$ & $(-8,-2,2,8)$ & $(-5,1,7,13)$ & $(-7,0,7,15)$ & $(-7,0,4,13)$ \\
$D$ & $(-5,2,7,14)$ & $(-9,-1,3,9)$ & $(-11,-4,4,11)$ & $(-10,-2,2,10)$ \\
\hline
\end{tabular}

TABle 13: Subtract $(-7,-2,4,14)$ from uncovered intervals.

\begin{tabular}{ccccc}
\hline & I & II & III & IV \\
\hline$A$ & $(-8,-2,2,8)$ & $(-20,-3,9,20)$ & $(-21,-6,6,21)$ & $(-21,-3,8,20)$ \\
$B$ & $(-4,1,6,12)$ & $(-8,-2,2,8)$ & $(-10,-4,3,11)$ & $(-7,1,5,12)$ \\
$C$ & $(-8,-2,2,8)$ & $(-19,-3,9,20)$ & $(-21,-4,9,22)$ & $(-21,-4,6,20)$ \\
$D$ & $(-5,2,7,14)$ & $(-9,-1,3,9)$ & $(-11,-4,4,11)$ & $(-10,-2,2,10)$ \\
\hline
\end{tabular}

TABLe 14: Transformation of Table 10 at $\alpha=0.5$.

\begin{tabular}{ccccc}
\hline & I & II & III & IV \\
\hline$A$ & {$[4,6.5]$} & {$[6.5,11.5]$} & {$[9.5,13]$} & {$[6.5,10.5]$} \\
$B$ & {$[7.5,10.5]$} & {$[4,6.5]$} & {$[7,11]$} & {$[6.5,9.5]$} \\
$C$ & {$[3,5.5]$} & {$[6,10.5]$} & {$[9.5,14]$} & {$[5,8.5]$} \\
$D$ & {$[7,11]$} & {$[3.5,6.5]$} & {$[6,10.5]$} & {$[3,6]$} \\
\hline
\end{tabular}

TABLE 15: Subtraction of the minimum interval in each column.

\begin{tabular}{ccccc}
\hline & I & II & III & IV \\
\hline$A$ & {$[-2.5,2.5]$} & {$[0,7.5]$} & {$[3,9]$} & {$[0,6.5]$} \\
$B$ & {$[1,6.5]$} & {$[-2.5,2.5]$} & {$[0.5,7]$} & {$[0,5.5]$} \\
$C$ & {$[-2.5,2.5]$} & {$[0.5,7.5]$} & {$[4,11]$} & {$[-0.5,5.5]$} \\
$D$ & {$[1,8]$} & {$[-2.5,3.5]$} & {$[0,7.5]$} & {$[-3,3]$} \\
\hline
\end{tabular}

TABLE 16: Subtraction of the minimum interval in each row.

\begin{tabular}{ccccc}
\hline & I & II & III & IV \\
$A$ & {$[-5,5]$} & {$[-2.5,10]$} & {$[-4.5,9]$} & {$[-3,9.5]$} \\
$B$ & {$[-1.5,9]$} & {$[-5,5]$} & {$[-7,7]$} & {$[-3,8.5]$} \\
$C$ & {$[-5,5]$} & {$[-2,10]$} & {$[-3.5,11]$} & {$[-3.5,8.5]$} \\
$D$ & {$[-1.5,10.5]$} & {$[-5,6]$} & {$[-7.5,7.5]$} & {$[-6,6]$} \\
\hline
\end{tabular}

TABLE 17: Subtract $[-3.5,8.5]$ from uncovered intervals.

\begin{tabular}{ccccc}
\hline & I & II & III & IV \\
\hline$A$ & {$[-5,5]$} & {$[-11,13.5]$} & {$[-13,12.5]$} & {$[-11.5,13]$} \\
$B$ & {$[-5,17.5]$} & {$[-5,5]$} & {$[-7,7]$} & {$[-3,8.5]$} \\
$C$ & {$[-5,5]$} & {$[-10.5,13.5]$} & {$[-12,14.5]$} & {$[-12,12]$} \\
$D$ & {$[-5,19]$} & {$[-5,6]$} & {$[-7.5,7.5]$} & {$[-6,6]$} \\
\hline
\end{tabular}

whose original function still exists until now. It is mandatory for buildings with the value of original extinct function such as ancient Egyptian temples and cemeteries. The methods of 
rehabilitating the building are multiple such as modification in the formation of internal voids by deleting part of the building or by creating architectural elements and shapes to which each of these methods is added. The aim is to reach to provide the maximum possible space required for the new activity while giving freedom and flexibility to exploit existing surfaces, resizing the interior space of the building, taking into account the proportions between the elements, height, and scale, ensuring that the essence of the artistic content is not compromised.

The desired objectives of reuse and employment of valuable buildings are numerous, whether they relate to the archaeological building itself by preserving its heritage and architectural values or related to its surroundings and its urban environment or related to the social aspect. We will address in the research study the means of optimal reuse of the building in terms of social and the built environment. Therefore, there are several social and urban goals for reuse that are clear as follows.

Opening the building of value to the public makes it relevant to the surrounding environment and enables us to link the past to the present. The social goals are given as follows:

Developing the national awareness to preserve the monumental buildings as a cultural heritage that must be preserved

Achieving the national social affiliation through focusing on the symbolic value

Upgrading the general taste of individuals, especially children

Preserving the historical character of the city and reinforcing the sense of pride of the citizens

Finding interconnectedness and communication between the building and its users through the job the building performs for the surrounding community

Preserving historic buildings aims to protect them as artistic works and historical evidence. Therefore, it must be developed and transformed to perform new jobs that meet the renewable needs of the society and achieve urban and environmental goals through

Development of the community surrounding the archaeological building, which helps to preserve the distinctive urban character of the historic district

Reuse of historical buildings and areas within the framework of the reality of land use determined by the city's planning studies

Forming a merger and cohesion between the old and new urban fabric of the historical areas of the existing cities

Achieving the sustainability goals by providing the raw materials as one of the environmental goals for reuse, as the reuse of an existing building achieves

There is a problem in achieving a balance between preserving valuable buildings and society benefiting from them, especially according to previous experiences. So, we suggest that "in case the cultural job is preserved, it should be reformulated as part of a development plan that benefits the residents of the region." One of the global models for reemploying valuable buildings, including distinguished models such as converting the historic Presidio Hospital in San Francisco, USA, into a residential building that includes 154 apartments, is now a distinctive sign in the region; dining tables have been placed between pumps, and some equipment have been added without affecting the original design of the building.

6.1. Case Study. We present the practical application study of several valuable buildings of Egypt. We study many places from the community and the surrounding environment's viewpoint, and an economic view, such as the Khedive Abbas I Palace in the city of Benha, Arab Republic of Egypt. It was established in the nineteenth century $\mathrm{AD}$ and reused as a school; then, the activity was changed from an educational to an administrator and reused as an administrative building for Benha University, see Figure 2.

The Saffron Palace in Cairo was reused as an administrative building for Ain Shams University, see Figure 3.

Al-Jazzar Palace, Shibin El-Kom, was reused as an administrative building for Menoufia University, see Figure 4.

Al-Jazeera Palace was established by Khedive Ismail to receive guests at the opening of the Suez Canal in 1869 AD, and in 1879, the palace was sold to Egyptian Hotels Company to pay part of the debt of Khedive Ismail and was transferred to Al-Jazeera Palace Hotel. After the collapse of the tourist movement in Egypt during the First World War, the palace was sold in 1919 to one of the Lebanese princes, Prince Habib Lotfallah, who turned it into a private residence. In 1962, the palace was nationalized and converted again to a hotel in the name of Omar Khayyam Hotel. Then, in the early seventies, Marriott International took over the management of the hotel (Figure 5).

The questionnaire was distributed to the users of each building and the surrounding environment and a group of specialists to determine the extent of the reality of the new use of the building and its suitability for the surrounding community environment and its suitability for its artistic, symbolic, and architectural value. The questionnaire was carried out in two phases: the first stage at the level of specialists and the suitability of the building for the new activity in design, urban, and planning and the second phase of the questionnaire at the level of the surrounding environment and the users of the building after changing the activity. The questionnaire was divided into four phases of evaluation for each building activity (inappropriate, acceptable, appropriate, and very appropriate) which are shown in Table 18. The activity that received less than $50 \%$ of the votes is considered inappropriate, the activity that obtained between 50 and $60 \%$ of the votes is considered acceptable, the activity with a percentage ranging from 60 to $80 \%$ of the votes is considered appropriate, and the activity with more than $80 \%$ of the votes is a very appropriate activity, see Table 19. The graph indicates the extent of approval of the new activity of the building according to the view of the surrounding environment and users which is 


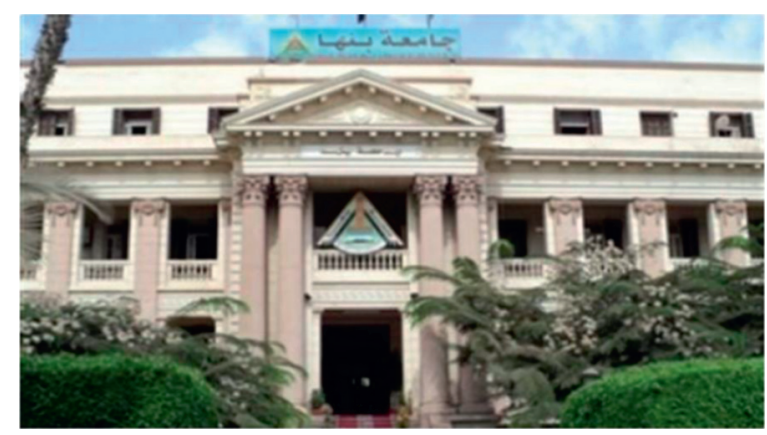

Figure 2: Khedive Abbas I Palace.

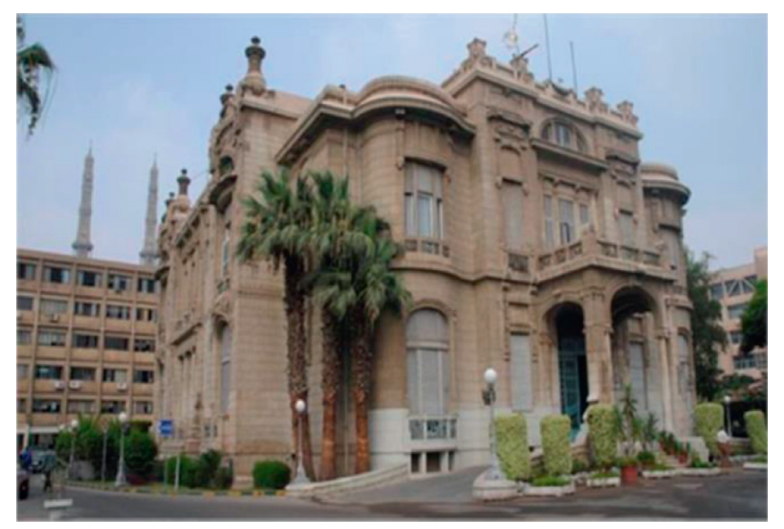

Figure 3: Saffron Palace.

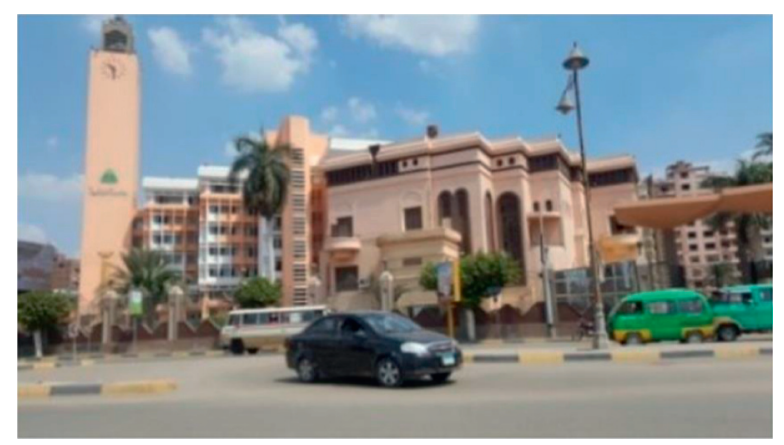

Figure 4: Al-Jazzar Palace.

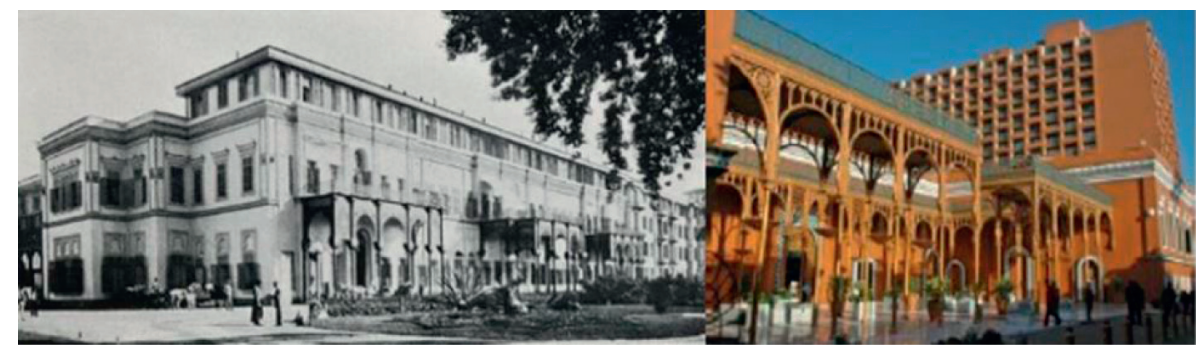

Figure 5: Al-Jazeera Palace.

shown in Figure 6. The flowchart indicates the extent of approval of the new activity of the building according to the viewpoint of the specialists which is shown in Figure 7.
The proposed method was used to solve the application with the same steps explained before and applied in the illustrative examples. The results were continuously advising the 
TABLE 18: Evaluation for each building activity.

\begin{tabular}{lcccccccc}
\hline & \multicolumn{2}{c}{$\begin{array}{c}\text { Administrative } \\
\text { building }\end{array}$} & \multicolumn{2}{c}{ A hotel } & \multicolumn{2}{c}{ A cultural building } & \multicolumn{2}{c}{ In another activity } \\
& \multicolumn{1}{c}{ I } & II & I & II & I & II & I & II \\
\hline Khedive Abbas I Palace & Unsuitable & Acceptable & Suitable & Suitable & Acceptable & Unsuitable & Unsuitable & Suitable \\
Saffron Palace & Unsuitable & Unsuitable & Unsuitable & Unsuitable & Acceptable & Suitable & Acceptable & Suitable \\
Al-Jazzar Palace & Unsuitable & Unsuitable & Unsuitable & Acceptable & Suitable & Suitable & Acceptable & Acceptable \\
Al-Jazeera Palace & Unsuitable & Suitable & Very convenient & Very convenient & Unsuitable & Suitable & Acceptable & Suitable \\
\hline
\end{tabular}

TABle 19: Comparison of the four palaces.

\begin{tabular}{lcccc}
\hline & Administrative & A hotel & A cultural & Another activity \\
\hline Khedive Abbas I Palace & {$[3,5.2]$} & 6.5 & {$[4,5.5]$} & {$[2,6.2]$} \\
Saffron Palace & {$[1,2]$} & {$[1,4]$} & {$[5.8,6.2]$} & {$[5.4,6.8]$} \\
Al-Jazzar Palace & {$[1,2.5]$} & {$[1.8,5.5]$} & 6.3 & 5.3 \\
Al-Jazeera Palace & {$[4,6]$} & 8.2 & {$[4.3,6.2]$} & {$[5,6]$} \\
\hline
\end{tabular}

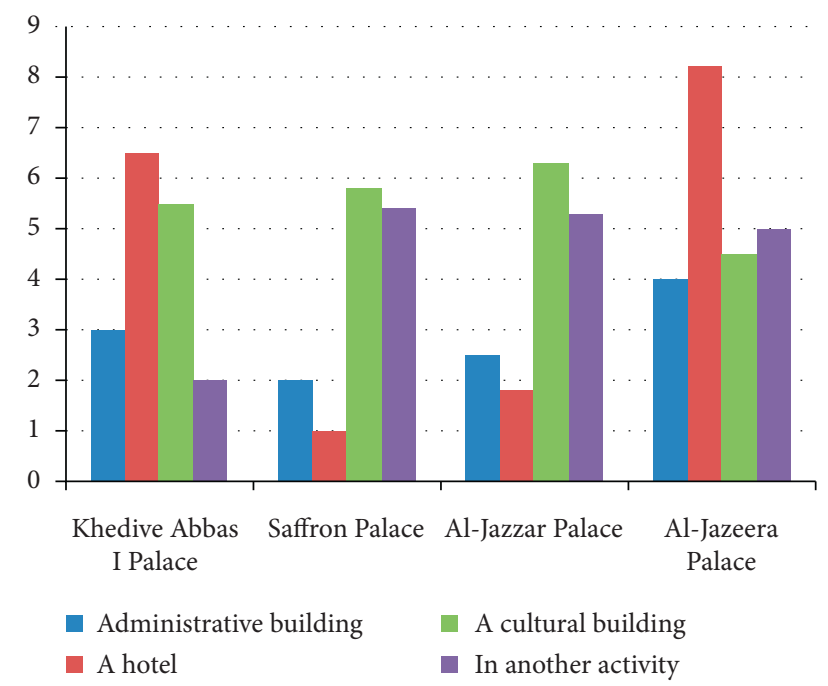

FIGURE 6: Graph indicating the extent of approval of the new activity of the building according to the view of the surrounding environment and users.

use of the Khedive Abbas I Palace as an administrative building for Benha University and searching for a new use of the Saffron Palace and the use of Al-Jazzar Palace as a cultural building for Menoufia Governorate and the continuation of the Al-Jazeera Palace to be used as a hotel building. This is according to the view of the surrounding environment, dealers, and specialists.

The research study resulted in the success of some cases of reuse of valuable buildings through thinking out of the ordinary and finding unconventional solutions and the failure of some attempts through the deterioration of the construction status of the building and the general condition of the building. The principle of community participation must be adopted in developing plans for reuse operations so that local communities are involved in all stages of these operations and even make local communities' part of them. Also, valuable buildings should be reused with an activity similar to the original activity for which the building was established or by studying the needs of the surrounding environment and adapting the new activity according to the requirements of the surrounding environment.

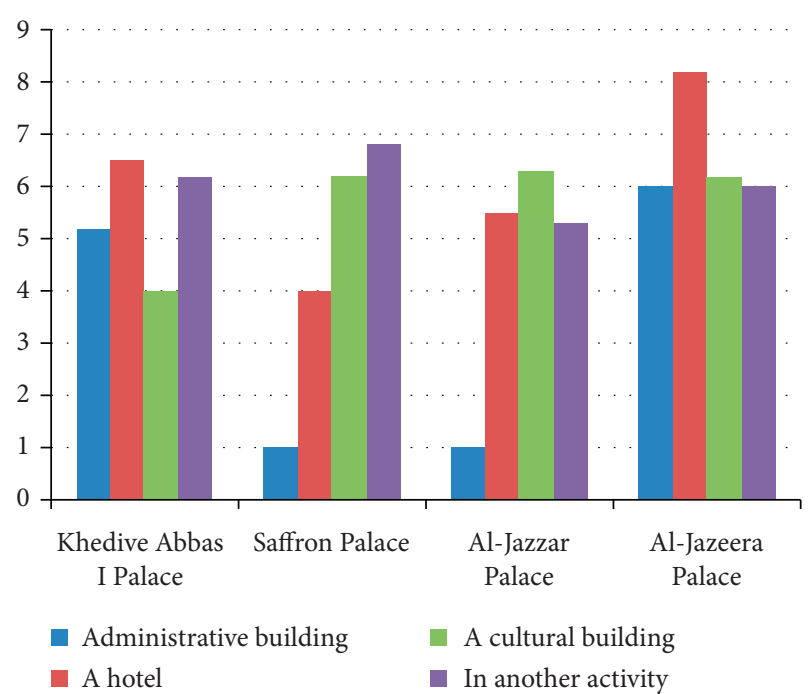

FIGURE 7: Flowchart indicating the extent of approval of the new activity of the building according to the viewpoint of the specialists.

\section{Conclusions}

In this paper, we introduce the modified Hungarian method for solving the interval and fuzzy AP. It is a novel and simple algorithm for solving the fuzzy and interval AP. We discussed finding a solution of an assignment problem in which cost coefficients are fuzzy numbers or intervals. The total optimal cost obtained by our method remains the same as that obtained by other researchers that convert the fuzzy cost into a crisp one by applying the ranking method. Also, we apply the modified Hungarian method in reuse of the valuable buildings in Egypt by making comparison between four valuable buildings that are reused in several activities for reaching the best benefit of building reuse, which should be matching with the basic purpose of the building and preserve on the value of the building. This method may be used in solving other types of optimization problems such as project schedules, transportation problems, and network flow problems. 


\section{Data Availability}

All the data used to support the findings of this study are included within the article.

\section{Conflicts of Interest}

The authors declare that there are no conflicts of interest.

\section{Authors' Contributions}

M. A. Elsisy conceived the presented idea. M. A. Elsisy and M. A. El Sayed developed the theoretical framework and performed the numerical calculations. A.S. Elsaadany and M. A. Elsisy carried out the rehabilitation problem of valuable buildings in Egypt. M. A. Elsisy, A.S. Elsaadany, and M. A. El Sayed worked out almost all the technical details, performed the numerical calculations for the suggested application, and wrote the manuscript. All authors discussed the results, commented on the manuscript, and contributed to the final manuscript.

\section{References}

[1] C. Lin and U. Wen, "A labeling algorithm for the fuzzy assignment problem," Fuzzy Sets and Systems, vol. 142, no. 3, pp. 373-391, 2004.

[2] P. Malini and M. Ananthanarayanan, "Solving fuzzy assignment problem using ranking of generalized trapezoidal fuzzy numbers," Indian Journal of Science and Technology, vol. 9, no. 20, pp. 1-4, 2016.

[3] A. Emrouznejad, M. Zerafat Angiz L, and W. Ho, "An alternative formulation for the fuzzy assignment problem," Journal of the Operational Research Society, vol. 63, no. 1, pp. 59-63, 2012.

[4] A. N. Gani and V. N. Mohamed, "Solution of a fuzzy assignment problem by using a new ranking method," International Journal of Fuzzy Mathematical Archive, vol. 2, pp. 8-16, 2013.

[5] D. Gurukumaresan, C. Duraisamy, R. Srinivasan, and V. Vijayan, "Optimal solution of fuzzy assignment problem with centroid methods," Materials Today: Proceedings, 2020, in Press.

[6] S. Kar, K. Basu, and S. Mukherjee, "Solution of generalized fuzzy assignment problem with restriction on costs under fuzzy environment," International Journal of Fuzzy Mathematics and Systems, vol. 4, no. 2, pp. 169-180, 2014.

[7] S. Kar, K. Basu, and S. Mukherjee, "Generalized fuzzy assignment problem with restriction on the cost of job under hesitant fuzzy environment," Opsearch, vol. 52, no. 3, pp. 401-411, 2015.

[8] D. W. Pentico, "Assignment problems: a golden anniversary survey," European Journal of Operational Research, vol. 176, no. 2, pp. 774-793, 2007.

[9] H. Liu, A. Abraham, and M. Clerc, "A hybrid fuzzy variable neighborhood particle swarm optimization algorithm for solving quadratic assignment problems," Journal of Universal Computer Science, vol. 13, no. 9, pp. 1309-1331, 2007.

[10] P. Tapkan, L. Özbakır, and A. Baykasoğlu, "Solving fuzzy multiple objective generalized assignment problems directly via bees algorithm and fuzzy ranking," Expert Systems with Applications, vol. 40, no. 3, pp. 892-898, 2013.
[11] R. Jonker and T. Volgenant, "Improving the Hungarian assignment algorithm," Operations Research Letters, vol. 5, no. 4, pp. 171-185, 1986.

[12] H. W. Kuhn, "The Hungarian method for the assignment problem," Naval Research Logistics Quarterly, vol. 2, no. 1-2, pp. 83-97, 1955.

[13] A. Kumar and A. Gupta, "Methods for solving fuzzy assignment problems and fuzzy travelling salesman problems with different membership functions," Fuzzy Information and Engineering, vol. 3, no. 1, pp. 3-21, 2011, p.

[14] P. Pandian and K. Kavitha, "A new method for solving fuzzy assignment problems," Annals of Pure and Applied Mathematics, vol. 1, no. 1, pp. 69-83, 2012.

[15] Y. L. P. Thorani and N. R. Shankar, "Application of fuzzy assignment problem," Advances in Fuzzy Mathematics, vol. 12, no. 4, pp. 911-939, 2017.

[16] R. Q. Mary and D. Selvi, Solving Fuzzy Assignment Problem Using Centroid Ranking Method, p. 55, IOP Publishing, Bristol, UK, 2018.

[17] V. Traneva and S. Tranev, "An interval-valued intuitionistic fuzzy approach to the assignment problem," in International Conference on Intelligent and Fuzzy Systems, pp. 1279-1287, Springer, Cham, Switzerland, 2019.

[18] S. Liu, K. Sheng, and J. Forrest, "On uncertain systems and uncertain models,” Kybernetes, vol. 41, no. 5-6, pp. 548-558, 2012.

[19] R. E. Moore, Interval Analysis, Prentice-Hall, Englewood Cliffs, NJ, USA, 1996.

[20] R. E. Moore, R. B. Kearfott, and M. J. Cloud, Introduction to Interval Analysis, SIAM Press, Philadelphia, PA, USA, 2009.

[21] S. K. Das, A. Goswami, and S. S. Alam, "Multiobjective transportation problem with interval cost, source and destination parameters," European Journal of Operational Research, vol. 117, no. 1, pp. 100-112, 1999.

[22] S. H. R. Hajiagha, H. A. Mahdiraji, and S. S. Hashemi, "Multiobjective linear programming with interval coefficients," Kybernetes, vol. 42, no. 3, pp. 482-496, 2013.

[23] H. Lu, G. Huang, and L. He, "An inexact rough-interval fuzzy linear programming method for generating conjunctive water-allocation strategies to agricultural irrigation systems," Applied Mathematical Modelling, vol. 35, no. 9, pp. 43304340, 2011.

[24] N. Gupta, "Optimization of fuzzy bi-objective fractional assignment Problem," Opsearch, vol. 56, no. 3, pp. 1091-1102, 2019.

[25] R. Nagarajan and A. Solairaju, "Computing improved fuzzy optimal Hungarian assignment problems with fuzzy costs under robust ranking techniques," International Journal of Computer Applications, vol. 6, no. 4, p. 6, 2010.

[26] Al-Hathloul, Tradition and Modernity in Architecture and Urbanism in the Islamic World, Symposium on Preserving Urban Heritage in the Emirates, Dubai, UAE, 1995.

[27] A. D. Botton, The Architecture of Happiness, Vintage International, New York, NY, USA, 2008.

[28] D. Cruickshank, Sir Banister Fletcher's A History of Architecture, Princeton Architectural Press, New York, NY, USA, 20th edition, 1996.

[29] S. Elttony, Urban Conservation of Older Housing Areas, Appropriating, the Process, IAHS, World Congress on Housing Trends Housing Projects, Miami Florida, USA, 1986.

[30] P. Goldberger, Why Architecture Matters, Yale University Press, New Haven, CT, USA, 2009.

[31] T. C. James, "Life in the pharaohs, translated by ahmed zuhair amin," Review: Mahmoud Maher Abdullah, General Book Authority, 1997. 
[32] S.-M. Chen, "Fuzzy system reliability analysis using fuzzy number arithmetic operations," Fuzzy Sets and Systems, vol. 64, no. 1, pp. 31-38, 1994.

[33] L. A. Zadeh, "Fuzzy sets," Information and Control, vol. 8, no. 3, pp. 338-353, 1965.

[34] P. S. Kumar and R. J. Hussain, "A method for finding an optimal solution of an assignment problem under mixed intuitionistic fuzzy environment," in Proceedings in International Conference on Mathematical Sciences (ICMS-2014), Elsevier, Seoul, South Korea, pp. 417-421, August 2014.

[35] Y. L. P. Thorani and N. R. Shankar, "Fuzzy assignment problem with generalized fuzzy numbers," Applied Mathematical Sciences, vol. 7, pp. 3511-3537, 2013. 